\title{
The Role of PTSD in Bi-directional Intimate Partner Violence in Military and Veteran Populations: A Research Review
}

OPEN ACCESS

Edited by:

Danny Horesh

Bar-llan University, Israel

Reviewed by:

Serge Brand,

University of Basel, Switzerland

Talya Greene,

University of Haifa, Israel

*Correspondence:

Gabriela Misca

g.misca@worc.ac.uk

Specialty section:

This article was submitted to

Psychopathology,

a section of the journal

Frontiers in Psychology

Received: 03 February 2017

Accepted: 31 July 2017

Published: 15 August 2017

Citation:

Misca G and Forgey MA (2017) The Role of PTSD in Bi-directional Intimate

Partner Violence in Military and

Veteran Populations: A Research Review. Front. Psychol. 8:1394.

doi: 10.3389/fpsyg.2017.01394

\author{
Gabriela Misca $^{1 *}$ and Mary Ann Forgey ${ }^{2}$ \\ ${ }^{1}$ Institute of Health and Society, University of Worcester, Worcester, United Kingdom, ${ }^{2}$ Graduate School of Social Services, \\ Fordham University, New York, NY, United States
}

Evidence supporting the higher prevalence of PTSD linked to combat-related trauma in military personnel and veteran populations is well-established. Consequently, much research has explored the effects that combat related trauma and the subsequent PTSD may have on different aspects of relationship functioning and adjustment. In particular, PTSD in military and veterans has been linked with perpetrating intimate partner violence (IPV). New research and theoretical perspectives suggest that in order to respond effectively to IPV, a more accurate understanding of the direction of the violence experienced within each relationship is critical. In both civilian and military populations, research that has examined the direction of IPV's, bi-directional violence have been found to be highly prevalent. Evidence is also emerging as to how these bi-directional violence differ in relation to severity, motivation, physical and psychological consequences and risk factors. Of particular importance within military IPV research is the need to deepen understanding about the role of PTSD in bi-directional IPV not only as a risk factor for perpetration but also as a vulnerability risk factor for victimization, as findings from recent research suggest. This paper provides a timely, critical review of emergent literature to disentangle what is known about bi-directional IPV patterns in military and veteran populations and the roles that military or veterans' PTSD may play within these patterns. Although, this review aimed to identify global research on the topic, the majority of research meeting the inclusion criteria was from US, with only one study identified from outside, from Canada. Strengths and limitations in the extant research are identified. Directions for future research are proposed with a particular focus on the kinds of instruments and designs needed to better capture the complex interplay of PTSD and bi-directional IPV in military populations and further the development of effective interventions.

Keywords: PTSD, IPV, military, veterans, domestic violence, couples, bi-directional IPV, combat-trauma

\section{BACKGROUND}

The wars in Iraq and Afghanistan have resulted in an unprecedented growth in research exploring the impact of war-zone deployment(s) on service members and their family functioning upon returning home. Among these issues, post-traumatic stress disorder (PTSD) has received extensive examination. Certain results have corroborated earlier findings involving Vietnam veterans and 
a consistent conclusion is that service members and veterans suffering from war-related PTSD have high prevalence rates of intimate partner violence (IPV) (e.g., Orcutt et al., 2003; Marshall et al., 2005; Taft et al., 2011; Smith et al., 2015; Trevillion et al., 2015). For example, in a recent systematic research review of military IPV prevalence, a $27.5 \%$ prevalence rate was found based on the studies reviewed of male veterans with PTSD who reported past year physical violence perpetration against female partners (Trevillion et al., 2015). This rate is substantially higher than the $12.7 \%$ IPV prevalence rate found in a nationally representative sample of participants with PTSD (Smith et al., 2015). While the majority of service members and veterans diagnosed with PTSD do not engage in IPV, military specific risk factors, such as length of deployment (McCarroll et al., 2003) and the type and level of combat exposure, including the killing of combatants and the witnessing of atrocities (e.g., Taft et al., 2005; Van Winkle and Safer, 2011) have been identified as factors that increase the risk of a service member or veteran with PTSD perpetrating IPV.

This body of research has increased understanding of which service members may be at risk of perpetration; however questions remain about the dynamic interplay of PTSD and IPV within the context of couple relationships. For example, the PTSD symptom of hyperarousal has been associated with IPV perpetration (Birkley et al., 2016); but how hyperarousal and other PTSD symptoms interact within the relationship context is not clear. Moreover, research highlighting correlations between combat-related PTSD and IPV has predominantly focused on male violence perpetration (Taft et al., 2005, 2009) and much less is known about the female service members' experience.

Equally important to gaining a fuller understanding of IPV and PTSD within the relationship context is the examination of the participation, if any, of the service member's spouse/partner in the violence. Civilian IPV research focused on understanding IPV directionality, as defined by the level and type of violence committed by each partner, identified bi-directional violence as the most prevalent pattern in both national and community samples (e.g., Capaldi and Owen, 2001; Caetano et al., 2005; Field and Caetano, 2005). Studies that further differentiated bidirectional violence found low-level bi-directional violence to be most prevalent (Capaldi and Owen, 2001; Williams and Frieze, 2005). Some studies have also identified unequal "asymmetrical" levels of violence or the primary aggressor within bi-directional patterns (Kernsmith, 2005; Temple et al., 2005; Williams and Frieze, 2005).

Military research that includes IPV directionality has been limited. In a methodological review, Rodrigues et al. (2015) identified seven studies that examined directionality with unilateral, bi-directional and asymmetrical patterns found (e.g., McCarroll et al., 2004; Chrysos et al., 2005; Forgey and Badger, 2006, 2010). Critically, less is known about the role of PTSD in these bi-directional patterns. Emerging findings suggest that the bi-directional pattern is the most prevalent when a service member has PTSD (Teten et al., 2009); moreover, the partner's use of aggression has been found to correlate with the service member IPV perpetration (LaMotte et al., 2015) and a service member's PTSD has also been identified as a risk factor for being a victim of IPV (Teten et al., 2009, 2010; LaMotte et al., 2014, 2015).

Complex typologies that go beyond describing the direction, type and level of IPV have been developed. Johnson and Ferraro (2000) proposed four patterns of violence organized by motivation; these include: intimate terrorism, violent resistance, mutual violence control and situational violence. While such typologies have greatly contributed to the understanding of various relationship contexts of IPV and have moved researchers and practitioners beyond thinking of IPV as a unitary phenomenon (Straus, 2011), their applicability to a military population is questionable due to the lack of consideration of specific military risk factors, including combat-related PTSD. More understanding about how these typologies fit or not within a military or veteran population is needed (Tinney and Gerlock, 2014). Of particular importance is a deeper understanding about the role of PTSD in IPV not only as a risk factor for perpetration but also as a vulnerability factor for victimization, as findings from recent research suggest (Teten et al., 2010; LaMotte et al., 2014, 2015).

While a significant body of research confirms the association between combat-related PTSD and IPV in military and veteran populations, examining in-depth the complex relationship of PTSD with the different patterns of IPV experienced by a military or veteran is critical. In light of the recent expansion of studies in this area, this timely review focuses specifically on what is known about IPV bi-directional patterns experienced in military and veteran populations and the roles that PTSD may play within these patterns.

\section{THE REVIEW}

This review systematically examined research on the role of service members' or veterans' PTSD in the IPV occurrence in couples comprising military service members or veterans involved in recent war conflicts. Searches of PsycINFO, MEDLINE, PILOTs, PubMed and Web of Science from 2003 to 2016 were performed. Searches included key words: (military/soldier*/arm*/combat/veteran*) AND (Iraq/Afghanistan/Enduring Freedom/Iraqi Freedom) and PTSD AND (IPV or [intimate partner AND (violence OR aggression)]. Further hand-searches were conducted on the bibliographies of the selected papers for other relevant articles and on papers that cited the selected studies.

Forty-four studies were retrieved and were individually assessed according to the following inclusion criteria: (1) reported data on both PTSD and IPV in couples of military personnel or veterans deployed to Iraq and Afghanistan; (2) included assessment of each partners' use of IPV (3) included assessment of the military personnel's PTSD (4) were peerreviewed and reported in English. This systematic evaluation identified 8 studies (see Table 1). In light of the extensive heterogeneity of the studies (in terms of samples, design and measures used), and their findings (which precluded a thematical approach to analysis), a narrative synthesis was employed. 


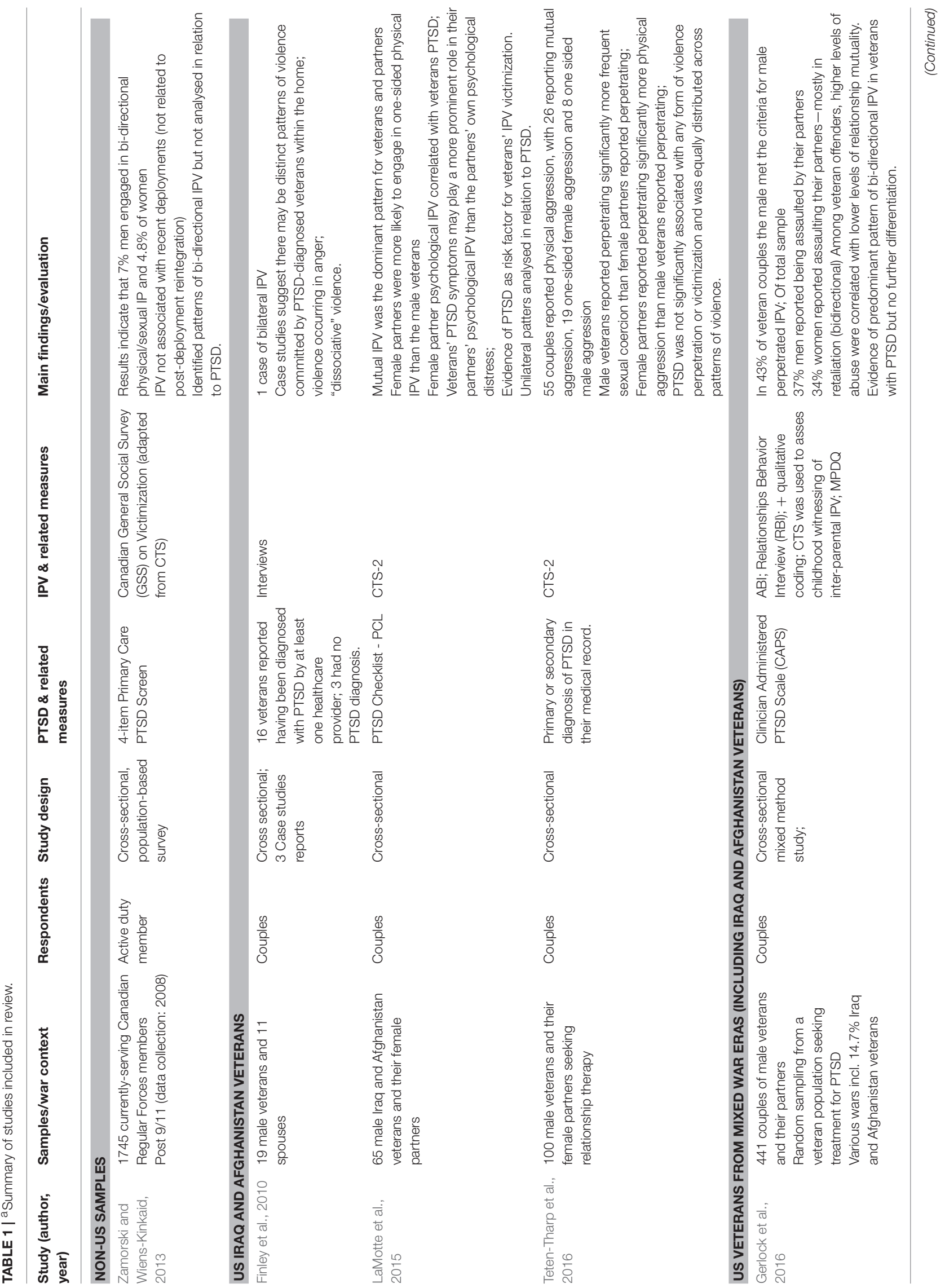




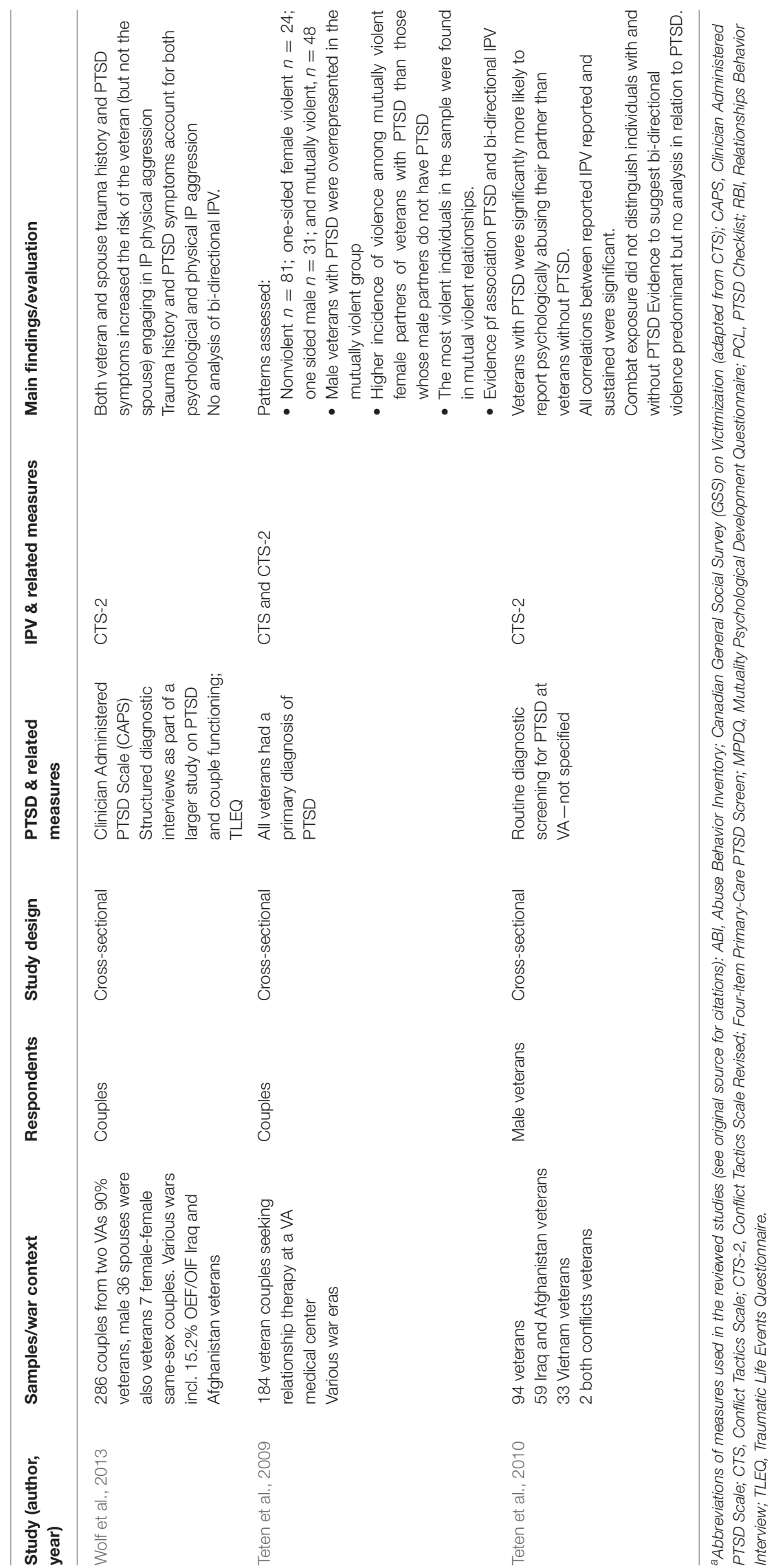




\section{FINDINGS}

The systematic searches identified one study that involved active duty service members in Canada and although the review aimed to identify global research on the topic, this was also the only study identified from outside the USA. Although, the focus of this review was on recent wars-i.e., conflict post 9/11- some of the studies included also veterans across older war eras. These studies were included in the review and discussed in terms of how their findings relate to recent war veterans.

The findings of studies included in the review are summarized in Table 1, and described in terms of the samples employed, including the war context, study design, and PTSD, IPV, and related measures; with the main findings evaluated and limitations highlighted. The studies were predominantly cross-sectional, with only two using mixed methods. As per inclusion criteria, all studies included a measure of military/veteran personnel's PTSD; however measure of PTSD for their partners'/spouses' were not employed across studies thus it is not possible to draw conclusions about the role of the partner's/spouse's PTSD in the couple's IPV.

Zamorski and Wiens-Kinkaid (2013) reported on a survey of IPV perpetration and victimization and their correlates, including PTSD symptoms, in a random sample of Canadian regular forces personnel $(87.81 \%$ male). Results indicate that $7 \%$ of male military personnel and $4.8 \%$ of female military personnel reported engagement in bi-directional physical/sexual IPV. While the study employed a large, non-clinical sample of Canadian active duty male and female personnel, the choice of measures and analysis itself provided limited understanding about the dynamics between IPV and the military personnel's PTSD within the active duty personnel's intimate relationships. The Canadian General Social Survey (GSS) on Victimization was used to measure service members' self-reports of any acts of IPV committed by either member of the couple over the course of their entire relationship. The military personnel's current PTSD symptoms were measured using the four-item Primary Care PTSD screen; however the types of symptoms reported were not analyzed, nor was any information explored regarding the traumatizing event(s) that were the source of these symptoms. The analyses employed did not examine how particular PTSD symptoms or events relate to IPV patterns within the relationships; moreover it was difficult to ascertain the timeframe of the reported IPV which may have occurred years prior to current symptoms of PTSD.

Two mixed methods studies were identified, employing quantitative and qualitative assessments to capture the complexities of IPV and PTSD interactions in veteran samples. Finley et al. (2010) reported on three patterns of IPV that emerged from a study of families living with combat-related PTSD). Analyzing descriptions of IPV occurring between male veterans diagnosed with PTSD and their female partners, three cases studies are described that illustrate the distinct patterns found: violence committed in anger; dissociative violence; and parasomniac/hypnopompic violence which is violence due to hyperarousal during sleep. The case of violence committed in anger was a case of bi-directional violence, in which the partner responded with violence in retaliation. Despite the lack of generalizability, these findings provided a detailed description of the dynamic interplay of PTSD symptoms and IPV patterns in veterans.

In another mixed method study, Gerlock et al. (2016) compared (male) veterans (from a variety of wars $(14.7 \%$ from Iraq and Afghanistan, 7.9\% Persian Gulf, 59\% Vietnam, 4.5\% Korean and $0.9 \%$ World War II) in treatment for PTSD who have perpetrated IPV and those who have not. IPV perpetration was assessed by combining veteran and their (female) partner's reports via interviews and questionnaires, allowing an exploration of the type, level and direction of the violence including, if there was a primary aggressor and if the violence was motivated by retaliation. This study found a significant correlation between PTSD symptom severity and IPV and a high concordance in veteran and their partner's reports of IPV.

The strengths of this study emanate from the use of an indepth mixed method assessment of PTSD severity and IPV, as well as an examination of perceived mutuality within a relationship and, importantly, secondary analyses of this data set found that mutuality mediated between PTSD symptom severity and IPV. The findings are limited, however, by the lack of exploring in more depth the motivational factors underlying the IPV beyond retaliation. And although PTSD symptom severity was examined, the role of PTSD symptoms themselves within each of the patterns was not, thus limiting the understanding of this dynamic. As certain types of combat exposure have been shown to increase the risk of IPV (Taft et al., 2005; Van Winkle and Safer, 2011), more examination of PTSD symptoms and the traumatic events underlying them is necessary to fully understand the dynamic interplay of PTSD and IPV in military and veteran populations, which becomes critical when samples combine veterans from across historical war eras, as in this study.

Among the quantitative studies identified, three involved veterans from different eras and two involved Iraq and Afghanistan veterans only. Wolf et al. (2013) examined the relationship between the veteran's PTSD and IPV in 296 couples of predominantly male veterans (majority from Vietnam and earlier wars, including $15.2 \%$ from Iraq and Afghanistan) and their female partners. The findings highlight that both veteran and spouse trauma history and PTSD symptoms increase the risk of the veteran but not the spouse engaging in IPV physical aggression; there was no relationship between any of the PTSD symptom-clusters and veteran perpetration of violence. Veteran combat exposure alone was not significantly correlated with physical or psychological aggression on the part of the veteran or spouse.

While each partner's use of violence in the last 6 months was explored, allowing an analysis of directionality, this analysis was not done and therefore the relationship of specific patterns of violence to PTSD was not examined. This is unfortunate since the study employed robust assessments of the veteran's PTSD, such as the Clinician Administered PTSD Scale (CAPS) to measure both the frequency and intensity of the PTSD symptoms within the past 6 months; and the Traumatic Life Events Questionnaire (TLEQ) to assess the type and level of 
traumatic events underlying the PTSD symptoms, allowing an exploration of the role, if any, of combat exposure in the violence perpetration. Although, no relationship was found between PTSD symptoms and combat exposure alone, this may be due to the majority of the participants being older Vietnam veterans whose combat exposure occurred decades ago and may have also experienced other types of trauma since.

Teten et al. $(2009,2010)$ examined the relationship between the veteran's PTSD and IPV in veterans and their partners seeking relationship therapy. In a sample of 184 couples involving veterans from various unspecified wars, Teten et al. (2009) identified three patterns of IPV: non-violent, mutually violent and one-sided violent. Veterans with a primary diagnosis of PTSD were overrepresented among couples reporting mutual violence. In a further sample of 94 Vietnam and Iraq and Afghanistan veterans, Teten et al. (2010) found that male Iraq and Afghanistan veterans with a PTSD diagnosis self-reported significantly more aggression toward their partner and also sustained more female perpetrated aggression than Iraq and Afghanistan veterans without PTSD or Vietnam veterans with PTSD.

While both of these studies report findings of high levels of mutual violence in veteran couples, there was limited analysis of the relationship between PTSD and these couples. Caution is needed as the data relied solely on veterans' self-reports of both IPV perpetration and victimization (Teten et al., 2009). Furthermore, all participants had a diagnosis of PTSD but there was no investigation of the symptom-clusters or the traumatic events that may be associated with the PTSD diagnosis. Consequently, little can be understood about the dynamic relationship between PTSD and IPV, other than the fact that a significant association was found.

Two studies reviewed focused exclusively on Iraq and Afghanistan male veterans and their female spouses. TetenTharp et al. (2016), in a sample of 100 couples, found 55 couples reporting physical aggression, with just over half reporting mutual aggression, and the rest reporting more one-sided female aggression than one-sided male aggression. Veteran's PTSD diagnosis, while prevalent within each pattern, was equally distributed and was not significantly associated with any specific pattern. Male veterans also reported perpetrating more frequent sexual coercion (operationalised as "insisting on sex when the partner did not want it") than female partners reported; while female partners reported perpetrating more physical aggression than male veterans reported perpetrating. In the absence of any understanding of motivation or impact, which were not explored, the gender differences found must be interpreted with caution.

In another study, LaMotte et al. (2015) reported findings from 65 Iraq and Afghanistan veterans (recruited on the basis of their combat exposure but not required to have a PTSD diagnosis) and their partners regarding their IPV. The findings confirm mutual IPV as the dominant pattern but only the relationship of PTSD to the unilateral patterns of violence was analyzed. Female partners were found to perpetrate higher levels of physical IPA than the male veterans did, according to both veteran and combined reports; and female partner psychological IPV correlated with veterans' PTSD.
This study is important as it brings evidence that PTSD in Iraq and Afghanistan veterans may act as a risk factor for $I P V$ victimization adding to our understanding of the complex relationship between combat-related PTSD and IPV. There are two potential explanations put forward for this interplay of PTSD's risk for perpetration and victimization: one refers to veteran's PTSD contributing to their IPV perpetration which in turn prompts partners' IPV as retaliation. The alternative explanation takes into account the carer's burden that veterans' PTSD places on their partners which in turn may lead to them react via IPV toward the veteran. The calculation of separate scores for the variety of physical acts of violence and for the frequency of the psychological violence acts allowed a more detailed understanding of who was doing what to whom in this study. However, the lack of enquiry into the motivation behind the violent acts committed (e.g., in control, defense, conflict) limited an understanding of these important dimensions. The severity of PTSD symptoms was measured and this allowed more understanding of their impact on the relationship; however, the specific symptomclusters were not examined, nor was the specific traumatizing event, although all veterans in the study had been combat exposed.

\section{CONCLUSIONS AND IMPLICATIONS FOR FUTURE RESEARCH}

All but one of the studies reviewed confirmed through analyses bi-directional as the predominant pattern in veteran and, to some extent, in military active duty populations. However, collectively there was limited examination of the dynamic between PTSD and bi-directional IPV due to the lack of explicit analysis of this relationship and the limitations of measurements and samples that were employed.

Truly capturing the dynamics of PTSD in couples experiencing IPV requires the robust measurement of both PTSD and IPV for both military and their partner. For PTSD, this means exploring symptoms along with the underlying traumatic events (Wolf et al., 2013; Semiatin et al., 2017). While the findings of the studies reviewed provided varied understanding of the veteran's PTSD symptomatology and etiology, none of the studies explored PTSD on the part of the partner and the role that it may play in the bi-directional nature of the violence. This exploration is critical to understanding the dynamics of PTSD and IPV and the potential role that secondary stress may play in the partner's reciprocal violence (Renshaw et al., 2011).

For IPV, robust measurement must encompass all dimensions, including type, level, frequency, physical impact (e.g., injury), emotional impact (e.g., fear) and motives. While instruments exist to capture PTSD symptoms and underlying traumatic events (e.g., CAPS, TLEQ), there is not, to our knowledge, an instrument to reliably measure all dimensions of IPV. Until such an instrument is developed and validated, qualitative interviewing alongside the CTS2 might provide a suitable interim methodological solution. 
When designing studies of the PTSD-IPV relationship, inclusion of other potential mediators identified in recent research, such as relationship mutuality (Gerlock et al., 2016), antisocial features (Taft et al., 2012) and social skills deficits (LaMotte et al., 2017) should be considered. The role of other military specific risk factors for IPV, for example, traumatic brain injury (TBI; Farrer et al., 2012) and substance abuse (Elbogen et al., 2014; Tinney and Gerlock, 2014) in the PTSD-IPV relationship also needs examination.

In addition to these measurement and design issues, attention must also be given to the populations from which the studies' samples are drawn. Most of the studies of veterans reviewed relied on samples recruited via Veteran Administration (VA), healthcare setting and clinical populations. Moreover, some studies included veterans from multiple war eras (e.g., Teten et al., 2009, 2010; Wolf et al., 2013; Gerlock et al., 2016) resulting in wide age range and large span of time in which the traumatic events possibly responsible for the PTSD symptoms may have occurred. Little has also been learned about the dynamics of combat-related PTSD in the intimate relationships of female active duty member and veterans and while many of the studies reviewed included female active duty members and veterans, they were a very small portion of the sample. Given the differences that may exist in terms of the female service members experience of both PTSD and IPV, separate studies are needed that focus on the female active duty and veteran population. When studying a military population attention must also be paid not only to

\section{REFERENCES}

Birkley, E. L., Eckhardt, C. I., and Dykstra, R. E. (2016). Posttraumatic stress disorder symptoms, intimate partner violence, and relationship functioning: a meta-analytic review. J. Trauma. Stress 29, 397-405. doi: 10.1002/jts.22129

Caetano, R., Ramisetty-Mikler, S., and Field, C. A. (2005). Unidirectional and bidirectional intimate partner violence among white, black, and hispanic couples in the United States. Violence Vict. 20, 393-406. doi: 10.1891/vivi.2005.20.4.393

Capaldi, D. M., and Owen, L. D. (2001). Physical aggression in a community sample of at-risk young couples: gender comparisons for high frequency, injury, and fear. J. Fam. Psychol. 15, 425. doi: 10.1037/0893-3200.15.3.425

Chrysos, E., Taft, C., King, L., and King, D. (2005). Gender, partner violence, and perceived family functioning among a sample of Vietnam veterans. Violence Vict. 20, 549-559. doi: 10.1891/088667005780927502

Dekel, R., and Monson, C. M. (2010). Military-related post-traumatic stress disorder and family relations: current knowledge and future directions. Aggress. Violent Behav. 15, 303-309. doi: 10.1016/j.avb.2010.03.001

Elbogen, E. B., Johnson, S. C., Wagner, H. R., Sullivan, C., Taft, C. T., and Beckham, J. C. (2014). Violent behavior and post-traumatic stress disorder in US Iraq and Afghanistan veterans. Br. J. Psychiatry 204, 368-375. doi: 10.1192/bjp.bp.113.134627

Farrer, T. J., Frost, R. B., and Hedges, D. W. (2012). Prevalence of traumatic brain injury in intimate partner violence offenders compared to the general population: a meta-analysis. Trauma. Violence Abuse 13, 77-82. doi: $10.1177 / 1524838012440338$

Field, C. A., and Caetano, R. (2005). Intimate partner violence in the US general population: progress and future directions. J. Interpers. Violence 20, 463-469. doi: 10.1177/0886260504267757

*Finley, E. P., Baker, M., Pugh, M. J., and Peterson, A. (2010). Patterns and perceptions of intimate partner violence committed by returning veterans with post-traumatic stress disorder. J. Fam. Violence 25, 737-743. doi: $10.1007 /$ s10896-010-9331-7 the gender of the military member but also the military status of each spouse, since dual military couples may face unique challenges.

More robust research that reliably measures PTSD and IPV patterns for the purpose of analyzing this relationship and attends to the issues of sample selection bias is sorely needed to inform clinical decision making for military and veteran couples dealing with PTSD and IPV. In recognition that PTSD impacts the couple relationship (Dekel and Monson, 2010), conjoint treatment options for PTSD have been put forward (Monson et al., 2008, 2009), however, if and how these models are applicable when IPV is also involved has yet to be addressed (Williston et al., 2015). Future research that better explains the roles of PTSD as risk factor for IPV perpetration and victimization for each partner in military and veteran samples is essential to the development of safe and appropriate treatment options for these couples.

\section{AUTHOR CONTRIBUTIONS}

Both authors contributed to literature searches and writing of this paper. Both authors approved the final manuscript.

\section{FUNDING}

Gabriela Misca's contribution to this manuscript was supported by a Fulbright Scholar Award.
Forgey, M. A., and Badger, L. (2006). Patterns of intimate partner violence among married women in the military: type, level, directionality and consequences. J. Fam. Violence 21, 369-380. doi: 10.1007/s10896-0069033-3

Forgey, M. A., and Badger, L. (2010). Patterns of intimate partner violence and associated risk factors among married enlisted female soldiers. Violence Vict. 25, 45-61. doi: 10.1891/0886-6708.25.1.45

*Gerlock, A. A., Szarka, J. G., Cox, K., and Harel, O. (2016). Comparing intimately violent to non-violent veterans in treatment for posttraumatic stress disorder. J. Fam. Violence 31, 667-678. doi: 10.1007/s10896-0169814-2

Johnson, M. P., and Ferraro, K. J. (2000). Research on domestic violence in the 1990s: making distinctions. J. Marriage Fam. 62, 948-963. doi: 10.1111/j.1741-3737.2000.00948.x

Kernsmith, P. (2005). Exerting power or striking back: a gendered comparison of motivations for domestic violence perpetration. Violence Vict. 20, 173-185. doi: 10.1891/vivi.2005.20.2.173

LaMotte, A. D., Taft, C. T., Weatherill, R. P., and Eckhardt, C. I. (2017). Social skills deficits as a mediator between PTSD symptoms and intimate partner aggression in returning veterans. J. Fam. Psychol. 31, 105-110. doi: 10.1037/fam0000215

*LaMotte, A. D., Taft, C. T., Weatherill, R. P., Scott, J. P., and Eckhardt, C. I. (2015). Correlates of intimate partner violence perpetrated by female partners of operation Iraqi Freedom and operation enduring freedom veterans. Partner Abuse 6, 143-156. doi: 10.1891/1946-6560.6.2.143

LaMotte, A. D., Taft, C. T., Weatherill, R. P., Scott, J. P., and Eckhardt, C. I. (2014). Examining intimate partner aggression assessment among returning veterans and their partners. Psychol. Assess. 26:8. doi: 10.1037/a0034579

Marshall, A. D., Panuzio, J., and Taft, C. T. (2005). Intimate partner violence among military veterans and active duty servicemen. Clin. Psychol. Rev. 25, 862-876. doi: 10.1016/j.cpr.2005.05.009

McCarroll, J. E., Ursano, R. J., Fan, Z., and Newby, J. H. (2004). Patterns of mutual and nonmutual spouse abuse in the US Army (1998-2002). Violence Vict. 19, 453-468. doi: 10.1891/vivi.19.4.453.64171 
McCarroll, J. E., Ursano, R. J., Newby, J. H., Liu, X., Fullerton, C. S., Norwood, A. E., et al. (2003). Domestic violence and deployment in US Army soldiers. J. Nerv. Ment. Dis. 191, 3-9. doi: 10.1097/00005053-200301000-00002

Monson, C. M., Fredman, S. J., and Adair, K. C. (2008). Cognitive-behavioral conjoint therapy for posttraumatic stress disorder: application to operation enduring and Iraqi Freedom veterans. J. Clin. Psychol. 64, 958-971. doi: $10.1002 /$ jclp.20511

Monson, C. M., Taft, C. T., and Fredman, S. J. (2009). Military-related PTSD and intimate relationships: from description to theory-driven research and intervention development. Clin. Psychol. Rev. 29, 707-714. doi: 10.1016/j.cpr.2009.09.002

Orcutt, H. K., King, L. A., and King, D. W. (2003). Male-perpetrated violence among Vietnam veteran couples: relationships with veteran's early life characteristics, trauma history, and PTSD symptomatology. J. Trauma. Stress 16, 381-390. doi: 10.1023/A:1024470103325

Renshaw, K. D., Allen, E. S., Rhoades, G. K., Blais, R. K., Markman, H. J., and Stanley, S. M. (2011). distress in spouses of service members with symptoms of combat related PTSD: Secondary traumatic stress or general psychological distress? J. Fam. Psychol. 25, 461-469. doi: 10.1037/a0023994

Rodrigues, A. E., Funderburk, J. S., Keating, N. L., and Maisto, S. A. (2015). A methodological review of intimate partner violence in the military: where do we go from here? Trauma. Violence Abuse16, 231-240. doi: $10.1177 / 1524838014526066$

Semiatin, J. N., Torres, S., LaMotte, A. D., Portnoy, G. A., and Murphy, C. M. (2017). Trauma exposure, PTSD symptoms, and presenting clinical problems among male perpetrators of intimate partner violence. Psychol. Violence 7, 91. doi: $10.1037 /$ vio0000041

Smith, K. Z., Smith, P. H., Violanti, J. M., Bartone, P. T., and Homish, G. G. (2015). Posttraumatic stress disorder symptom clusters and perpetration of intimate partner violence: findings from a US nationally representative sample. J. Trauma. Stress 28, 469-474. doi: 10.1002/jts.22048

Straus, M. A. (2011). Gender symmetry and mutuality in perpetration of clinicallevel partner violence: empirical evidence and implications for prevention and treatment. Aggress. Violent Behav. 16, 279-288. doi: 10.1016/j.avb.2011. 04.010

Taft, C. T., Kachadourian, L. K., Suvak, M. K., Pinto, L. A., Miller, M. M., Knight, J. A., et al. (2012). Examining impelling and disinhibiting factors for intimate partner violence in veterans. J. Fam. Psychol. 26:285. doi: 10.1037/a0027424

Taft, C. T., Pless, A. P., Stalans, L. J., Koenen, K. C., King, L. A., and King, D. W. (2005). Risk factors for partner violence among a national sample of combat veterans. J. Consult. Clin. Psychol. 73:151. doi: 10.1037/0022-006X.73.1.151

Taft, C. T., Watkins, L. E., Stafford, J., Street, A. E., and Monson, C. M. (2011). Posttraumatic stress disorder and intimate relationship problems: a metaanalysis. J. Consult. Clin. Psychol. 79, 22-33. doi: 10.1037/a0022196

Taft, C. T., Weatherill, R. P., Woodward, H. E., Pinto, L. A., Watkins, L. E., Miller, M. W., et al. (2009). Intimate partner and general aggression perpetration among combat veterans presenting to a posttraumatic stress disorder clinic. Am. J. Orthopsychiatry 79:461. doi: 10.1037/a0016657

Temple, J. R., Weston, R., and Marshall, L. L. (2005). Physical and mental health outcomes of women in nonviolent, unilaterally violent, and mutually violent relationships. Violence Vict. 20, 335-359. doi: 10.1891/vivi.20. 3.335
*Teten, A. L., Schumacher, J. A., Taft, C. T., Stanley, M. A., Kent, T. A., Bailey, S. D., et al. (2010). Intimate partner aggression perpetrated and sustained by male Afghanistan, Iraq, and Vietnam veterans with and without posttraumatic stress disorder. J. Interpers. Violence 25, 1612-1630. doi: 10.1177/08862605093 54583

*Teten, A. L., Sherman, M. D., and Han, X. (2009). Violence between therapy-seeking veterans and their partners prevalence and characteristics of nonviolent, mutually violent, and one-sided violent couples. J. Interpers. Violence 24, 111-127. doi: 10.1177/08862605083 15782

*Teten-Tharp, A. L., Sherman, M. D., Bowling, U., and Townsend, B. J. (2016). Intimate partner violence between male Iraq and Afghanistan veterans and their female partners who seek couples therapy. J. Interpers. Violence 31, 1095-1115. doi: 10.1177/0886260514564067

Tinney, G., and Gerlock, A. A. (2014). Intimate partner violence, military personnel, veterans, and their families. Fam. Court Rev. 52, 400-416. doi: $10.1111 /$ fcre. 12100

Trevillion, K., Williamson, E., Thandi, G., Borschmann, R., Oram, S., and Howard, L. M. (2015). A systematic review of mental disorders and perpetration of domestic violence among military populations. Soc. Psychiatry Psychiatr. Epidemiol. 50, 1329-1346. doi: 10.1007/s00127-0151084-4

Van Winkle, E. P., and Safer, M. A. (2011). Killing versus witnessing in combat trauma and reports of PTSD symptoms and domestic violence. J. Trauma. Stress 24, 107-110. doi: 10.1002/jts.20614

Williams, S. L., and Frieze, I. H. (2005). Patterns of violent relationships, psychological distress, and marital satisfaction in a national sample of men and women. Sex Roles 52, 771-784. doi: 10.1007/s11199-0054198-4

Williston, S. K., Taft, C. T., and VanHaasteren, K. O. (2015). Military veteran perpetrators of intimate partner violence: challenges and barriers to coordinated intervention. Aggress. Violent Behav. 21, 55-60. doi: $10.1016 /$ j.avb.2015.01.008

*Wolf, E. J., Harrington, K. M., Reardon, A. F., Castillo, D., Taft, C. T., and Miller, M. W. (2013). A dyadic analysis of the influence of trauma exposure and posttraumatic stress disorder severity on intimate partner aggression. $J$. Trauma. Stress 26, 329-337. doi: $10.1002 /$ jts.21805

*Zamorski, M. A., and Wiens-Kinkaid, M. E. (2013). Cross-sectional prevalence survey of intimate partner violence perpetration and victimization in Canadian military personnel. BMC Public Health 13:1019. doi: 10.1186/1471-2458-13-1019

Conflict of Interest Statement: The authors declare that the research was conducted in the absence of any commercial or financial relationships that could be construed as a potential conflict of interest.

Copyright (c) 2017 Misca and Forgey. This is an open-access article distributed under the terms of the Creative Commons Attribution License (CC BY). The use, distribution or reproduction in other forums is permitted, provided the original author(s) or licensor are credited and that the original publication in this journal is cited, in accordance with accepted academic practice. No use, distribution or reproduction is permitted which does not comply with these terms.

*Denotes study included in the review. 